\title{
Blocking effect of crystal-glass interface in lanthanum doped barium strontium titanate glass-ceramics
}

\author{
Xiangrong Wang ${ }^{a}$, Yong Zhang ${ }^{\mathrm{a}, *}$, Ivan Baturin ${ }^{\mathrm{b}}$, Tongxiang Liang ${ }^{\mathrm{a}}$ \\ a Beijing Fine Ceramics Laboratory, State Key Laboratory of New Ceramics and Fine Processing, Institute of Nuclear and New Energy Technology, Tsinghua \\ University, Beijing 100084, China \\ ${ }^{\mathrm{b}}$ Ferroelectric Laboratory, Institute of Natural Science, Ural Federal University, Ekaterinburg 620000, Russia
}

\section{A R T I C L E IN F O}

\section{Article history:}

Received 10 December 2012

Received in revised form 18 April 2013

Accepted 27 May 2013

Available online 4 June 2013

\section{Keywords:}

A. Ceramics

A. Interface

C. Impedance spectroscopy

D. Microstructure

\begin{abstract}
A B S T R A C T
The microstructures and dielectric properties in $\mathrm{La}_{2} \mathrm{O}_{3}$-doped barium strontium titanate glass-ceramics have been investigated by scanning electron microscopy (SEM) and impedance spectroscopy. SEM analysis indicated that $\mathrm{La}_{2} \mathrm{O}_{3}$ additive decreases the average crystallite size. Impedance spectroscopy revealed that the positions of $Z^{\prime \prime}$ and $M^{\prime \prime}$ peaks are close for undoped samples. When $\mathrm{La}_{2} \mathrm{O}_{3}$ concentration is $0.5 \mathrm{~mol} \%$, the $Z^{\prime \prime}$ and $M^{\prime \prime}$ peaks show a significant mismatch. Furthermore, these peaks separate obviously for $1.0 \mathrm{~mol} \% \mathrm{La}_{2} \mathrm{O}_{3}$ addition. With increasing $\mathrm{La}_{2} \mathrm{O}_{3}$ concentration, the contribution of the crystallite impedance becomes smaller, while the contribution of the crystal-glass interface impedance becomes larger. More interestingly, it was found that $\mathrm{La}_{2} \mathrm{O}_{3}$ additive increases blocking factor of the crystal-glass interface in the temperature range of $250-450{ }^{\circ} \mathrm{C}$. This may be attributed to a decrease of activation energy of the crystallite and an increase of the crystal-glass interface area.
\end{abstract}

(c) 2013 Elsevier Ltd. All rights reserved.

\section{Introduction}

Energy storage capability and reliability of capacitors are of utmost importance for various current and future demanding applications. As a result, in recent years, significant efforts have been made to develop dielectric materials with high energy storage density $[1,2]$. Among these materials, barium strontium titanate $\mathrm{Ba}_{x} \mathrm{Sr}_{1-x} \mathrm{TiO}_{3}$ (BST) ferroelectric glass-ceramics have been recognized as one of the most promising candidates in terms of their high dielectric constants and high breakdown strengths [3-5]. Generally, glass-ceramic materials have a pore-free and fine grained microstructure which is highly desirable for ceramics used in capacitors [6]. The fabrication of the ferroelectric glass-ceramics by the ferroelectric phase crystallization from the glass has proved to be a useful complement to the technology of electronic ceramics $[7,8]$.

Of particular interest is the comparison of such ferroelectric glass-ceramics with corresponding pure ferroelectric ceramics. Although the defect chemistry of undoped and doped barium titanate $\left(\mathrm{BaTiO}_{3}\right)$ ceramics is well studied [9-11], many discrepancies still exist between experimental results and theoretical interpretations, especially for lanthanum doped barium titanate glass-ceramics [12,13]. Colossal dielectric permittivity was observed in $\mathrm{Ba}_{0.95} \mathrm{La}_{0.05} \mathrm{TiO}_{3-x}$ ceramics [14,15]. This effective

\footnotetext{
* Corresponding author. Tel.: +86 10 80194055; fax: +86 1089796022.

E-mail address: yzhang@tsinghua.edu.cn (Y. Zhang).
}

permittivity is attributed to interfacial polarization, which is formed between semiconducting grains and insulating grain boundaries in the ceramics.

In $\mathrm{La}_{2} \mathrm{O}_{3}$-doped barium titanate ceramics a replacement of $\mathrm{Ba}^{2+}$ on the A-site by La ${ }^{3+}\left(\mathrm{La}^{3+}\right.$ ion is too large to replace Ti on the B-site) leads to charge imbalance which must be compensated by either cation vacancies on the A- or B-site (ionic compensation), or electrons (electronic compensation). Three simple possible compensation mechanisms can be identified $[9,10]$ :

$$
\begin{aligned}
& \mathrm{La}_{2} \mathrm{O}_{3}+2 \mathrm{TiO}_{2} \rightarrow 2 \mathrm{La}_{\mathrm{Ba}}^{\cdot}+2 \mathrm{Ti}_{\mathrm{Ti}}^{\times}+6 \mathrm{O}_{\mathrm{O}}^{\times}+\frac{1}{2} \mathrm{O}_{2}+2 \mathrm{e}^{\prime} \\
& 2 \mathrm{La}_{2} \mathrm{O}_{3}+3 \mathrm{TiO}_{2} \rightarrow 4 \mathrm{La}_{\mathrm{Ba}}^{\cdot}+3 \mathrm{Ti}_{\mathrm{Ti}}^{\times}+12 \mathrm{O}_{\mathrm{O}}^{\times}+\mathrm{V}_{\mathrm{Ti}}^{\prime \prime \prime} \\
& \mathrm{La}_{2} \mathrm{O}_{3}+3 \mathrm{TiO}_{2} \rightarrow 2 \mathrm{La}_{\mathrm{Ba}}^{\cdot}+3 \mathrm{Ti}_{\mathrm{Ti}}^{\times}+9 \mathrm{O}_{\mathrm{O}}^{\times}+\mathrm{V}_{\mathrm{Ba}}^{\prime \prime}
\end{aligned}
$$

In addition, a direct donor doping, especially at low donor concentration, is considered as the mechanism of the charge compensation and the appearance of semiconductive properties [16]. But the mechanism by which the normally insulating BST glass-ceramics becomes semiconducting is uncertain and has been rarely ever reported [17].

It is well known that in polycrystalline $\mathrm{BaTiO}_{3}$ ceramic materials grain boundaries often have a significant influence on material properties. Study of the grain boundary properties is essential to the design of the $\mathrm{BaTiO}_{3}$-based ceramic materials and to the optimization of their performance. However, the preparation of the $\mathrm{BaTiO}_{3}$ 
glass-ceramics is generally based on total or partial conversion of silicate glasses to the $\mathrm{BaTiO}_{3}$ crystalline phase. The glass composition must be chosen properly to minimize the interactions between the $\mathrm{BaTiO}_{3}$ crystalline phase and the residual glass. The different doping mechanisms in $\mathrm{BaTiO}_{3}$ ceramics provide a framework for conducting experiment on the $\mathrm{BaTiO}_{3}$ glass-ceramics. Notably, the grain boundary models for the $\mathrm{BaTiO}_{3}$ ceramics are in agreement with the experimental results [17]. However, such models are inherently incapable of elucidating the mechanisms of ionic transport phenomena for the BST glass-ceramics. Therefore, they must be supplemented by electrical continuity and blocking effect. In our previous publications it has been reported that the interfacial polarization significantly affects the dielectric and energy storage properties of the ferroelectric glass-ceramics $[5,12,18]$.

In the present work, the complex impedance analysis is employed to obtain information about the ionic transport phenomenon in the BST glass-ceramics. The technique of complex impedance allows us to separate the individual contributions of the crystallite and the crystal-glass interface from the total impedance spectroscopy. Using this technique, the ionic transport phenomenon in each component can be understood to explain the blocking effect of the crystal-glass interface in the glass-ceramics.

\section{Experimental procedure}

The glass-ceramic samples with the composition of $a \mathrm{BaO}-$ $b \mathrm{SrO}-29 \mathrm{TiO}_{2}-22 \mathrm{SiO}_{2}-12 \mathrm{Al}_{2} \mathrm{O}_{3}-2.4 \mathrm{BaF}_{2}-\chi \mathrm{La}_{2} \mathrm{O}_{3} \quad(x=0,0.5$ and $1.0 \mathrm{~mol} \%$ ) were prepared by a melt-annealing technique. The ratio of $\mathrm{BaO}$ and $\mathrm{SrO}$ was kept $4: 1$, at the same time, the amount of A-site ions was kept $34.6 \mathrm{~mol} \%$, that is, $a+b+2 x=34.6 \mathrm{~mol} \%$. The powder containing appropriate amounts of $\mathrm{BaCO}_{3}, \mathrm{SrTiO}_{3}, \mathrm{TiO}_{2}$, $\mathrm{SiO}_{2}, \mathrm{Al}_{2} \mathrm{O}_{3}, \mathrm{BaF}_{2}$ and $\mathrm{La}_{2} \mathrm{O}_{3}$ (all with purity $\geq 99 \%$ ) was ball-milled for $4 \mathrm{~h}$ using zirconia balls and ethanol as media, and then dried at $120^{\circ} \mathrm{C}$ for $2 \mathrm{~h}$. After drying, the mixture was melted in a platinum crucible at $1550{ }^{\circ} \mathrm{C}$ for $3 \mathrm{~h}$. Cylindrical glass ingot was prepared by casting the molten glass into a copper mold with an inner cavity of $30 \mathrm{~mm}$ diameter and $20 \mathrm{~mm}$ height. Then the casted glass was immediately annealed at $650{ }^{\circ} \mathrm{C}$ for $3 \mathrm{~h}$ to relieve residual stresses. The as-annealed glass was cut to obtain thin slabs with the thickness of $1 \mathrm{~mm}$. Finally, samples with different $\mathrm{La}_{2} \mathrm{O}_{3}$ concentrations were heated in air at $700-1000{ }^{\circ} \mathrm{C}$ for $2 \mathrm{~h}$ to convert the glasses into glass-ceramics. Both sides of the crystallized samples were covered with silver paint and then fired at $550{ }^{\circ} \mathrm{C}$ for $30 \mathrm{~min}$ in order to ensure good electrical contacts for the impedance measurements.

X-ray diffraction (Model-D8 Advance, Bruker AXS, Karlsruhe, Germany) and field emission scanning electron microscopy (Model Quanta 200 FEG, FEI, Eindhoven, The Netherlands) were used to investigate the phase evolution and microstructure, respectively. Complex impedance spectrum was obtained at an input signal level of $2 \mathrm{~V}$ in a wide temperature range of $250-450{ }^{\circ} \mathrm{C}$ using a computer-controlled impedance analyzer (HP4194, Hewlett-Packard, CA, USA) in the frequency range of $20 \mathrm{~Hz}$ to $1 \mathrm{MHz}$.

\section{Results and discussion}

The typical X-ray diffraction (XRD) patterns for the studied glass-ceramic samples with different $\mathrm{La}_{2} \mathrm{O}_{3}$ concentrations indicate that perovskite $(\mathrm{Ba}, \mathrm{Sr}) \mathrm{TiO}_{3}$ is a major crystalline phase and feldspar $\mathrm{BaAl}_{2} \mathrm{Si}_{2} \mathrm{O}_{8}$ is a minor phase in all the glass-ceramic samples, as shown in Fig. 1. As can be seen in Fig. 1, the intensity of XRD peaks of the $(\mathrm{Ba}, \mathrm{Sr}) \mathrm{TiO}_{3}$ crystalline phase increases with increasing $\mathrm{La}_{2} \mathrm{O}_{3}$ concentration. When the $\mathrm{La}_{2} \mathrm{O}_{3}$ concentration is increased to $1.0 \mathrm{~mol} \%$, the intensity of the major diffraction peaks of the $(\mathrm{Ba}, \mathrm{Sr}) \mathrm{TiO}_{3}$ crystalline phase significantly increases, which illustrates the trend in the relative content of $(\mathrm{Ba}, \mathrm{Sr}) \mathrm{TiO}_{3}$ crystalline phase. And this also shows that $\mathrm{La}_{2} \mathrm{O}_{3}$ acts as a nucleating agent and promotes the crystallization of the major crystalline phase from the glass matrix. Therefore, in this glass system, phase separation took place when the appropriate concentration of $\mathrm{La}_{2} \mathrm{O}_{3}$ was added. It is well known that there is a large difference in ionic radius between $\mathrm{Ba}^{2+}$ and $\mathrm{La}^{3+}$, being 0.161 and $0.136 \mathrm{~nm}$, respectively. The substitution of $\mathrm{La}^{3+}$ for $\mathrm{Ba}^{2+}$ ion creates lattice distortion, which could lead to limited solubility of $\mathrm{La}^{3+}$ on the A-site for the perovskite $(\mathrm{Ba}, \mathrm{Sr}) \mathrm{TiO}_{3}$. This tendency is consistent with the influence of $\mathrm{La}_{2} \mathrm{O}_{3}$ concentration on the average crystallite size shown in Fig. 2.

SEM investigations have been conducted to ascertain the effect of $\mathrm{La}_{2} \mathrm{O}_{3}$ concentration on the microstructures of the BST glassceramics. The specimens were prepared by polishing and etching with $0.5 \mathrm{wt} \% \mathrm{HF}$ solution. Fig. 2 shows the microstructures of the BST glass-ceramics with different $\mathrm{La}_{2} \mathrm{O}_{3}$ concentrations. Addition of small amount of $\mathrm{La}_{2} \mathrm{O}_{3}$ does not change the microstructural morphology of the BST glass-ceramics. Submicrometer crystallites are uniformly distributed in the glass matrix. On the other hand, an increase of $\mathrm{La}_{2} \mathrm{O}_{3}$ concentration up to $1.0 \mathrm{~mol} \%$ leads to an abrupt decrease of the average crystallite size [Fig. 2(c)]. Such behavior could be related to the limited solid solubility of lanthanum in the BST lattice. The addition of $1.0 \mathrm{~mol}_{2} \mathrm{La}_{2} \mathrm{O}_{3}$ may go beyond the solid solubility limit of $\mathrm{La}_{2} \mathrm{O}_{3}$ in the BST lattice. Thus this will probably result in the segregation at the crystal-glass interface thereby inhibiting a growth of the crystallites and hence leading to the decrease of the average crystallite size.

The impedance analysis combined with the modulus spectroscopy is a powerful technique, which provides important information about the contribution of different electroactive regions such as crystalline phase, crystal-glass interface and glass matrix to the relaxation process. Combined impedance $Z^{\prime \prime}$ and modulus $M^{\prime \prime}$ plots are particularly useful to understand the heterogeneity of the electrical properties. Fig. 3 shows the variation of both $Z^{\prime \prime}$ and $M^{\prime \prime}$ with the frequency for the $\mathrm{La}_{2} \mathrm{O}_{3}$-doped glass-ceramic samples at different measurement temperatures. It can be seen that both $Z^{\prime \prime}$ and $M^{\prime \prime}$ peaks for all samples appear in the studied frequency and temperature ranges. All peaks shift toward higher frequencies with the increase of measurement temperature. This indicates that high temperatures trigger the relaxation processes for the $\mathrm{La}_{2} \mathrm{O}_{3}$-doped glass-ceramics. Additionally, it can be shown that the $Z^{\prime \prime}$ maximum decreases with the increase of the temperature, while the change

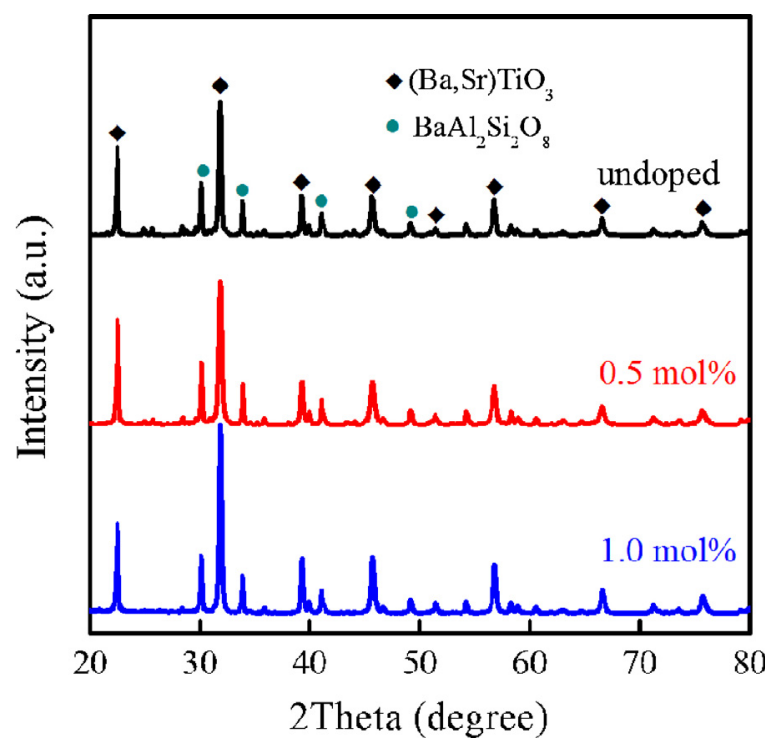

Fig. 1. X-ray diffraction patterns for the BST glass-ceramics with different $\mathrm{La}_{2} \mathrm{O}_{3}$ concentrations. 

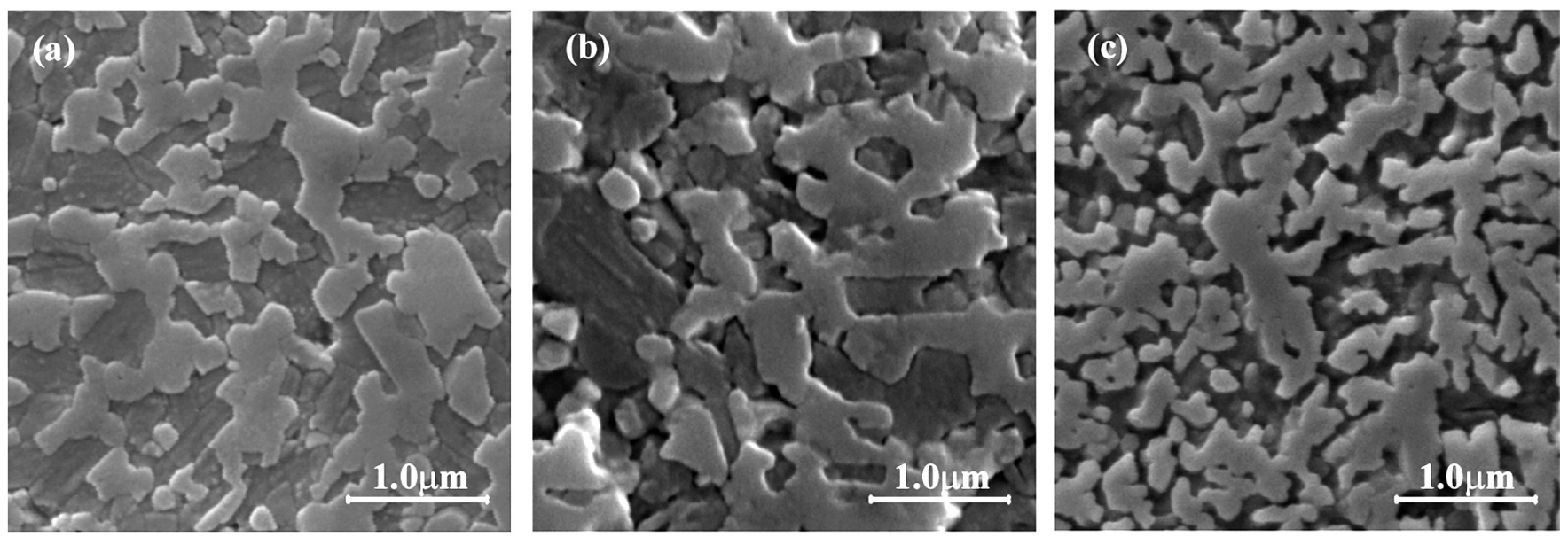

Fig. 2. SEM micrographs of the BST glass-ceramics with different $\mathrm{La}_{2} \mathrm{O}_{3}$ concentrations: (a) undoped; (b) 0.5 mol\%; (c) 1.0 mol\%.

of $M^{\prime \prime}$ maximum is essentially weaker. This suggests that the increase of the temperature results in a decreased resistivity, while the capacitance is practically independent of the temperature.

The difference in the impedance $Z^{\prime \prime}$ and modulus $M^{\prime \prime}$ plots for the samples with different $\mathrm{La}_{2} \mathrm{O}_{3}$ concentrations was observed. For the undoped ceramics, the peak positions of the $Z^{\prime \prime}$ and the $M^{\prime \prime}$ are close, but not exactly coincident in frequency, indicating the presence of long range conductivity [19]. In the studied glassceramics with $0.5 \mathrm{~mol} \% \mathrm{La}_{2} \mathrm{O}_{3}$ addition, the $Z^{\prime \prime}$ and $M^{\prime \prime}$ peaks show the increased separation from each other, which is an evidence of the localized conduction and a deviation from an ideal Debye-like behavior in which the $Z^{\prime \prime}$ and $M^{\prime \prime}$ peaks are coincident. Much larger separation of the $Z^{\prime \prime}$ and $M^{\prime \prime}$ peaks in the glass-ceramics with $1.0 \mathrm{~mol} \% \mathrm{La}_{2} \mathrm{O}_{3}$ addition is due to two different relaxation processes. These results suggest that the relaxation mechanisms in the glass-ceramics are changed from localized process to dynamic one occurring at different frequencies [20] with the increase of $\mathrm{La}_{2} \mathrm{O}_{3}$ concentration.

In order to model the electrical response and extract resistance and capacitance of each electroactive element, an equivalent circuit, shown in Fig. 4(a), was used to fit the experimental data using the Zsimpwin Electrochemical Impedance Spectroscopy
Data Analysis software (Version 3.10). In the equivalent circuit, $Q$ and $R$ denote constant phase element (complex impedance $\left.Z_{Q}^{*}=\left(Z_{Q}^{0}(i w)^{\alpha}\right)^{-1}\right)$ and resistance. Fig. $4(\mathrm{~b})-(\mathrm{d})$ shows the complex impedance plots of experimental (black filled squares) and fitting (red line) data at $390{ }^{\circ} \mathrm{C}$ for the samples with different $\mathrm{La}_{2} \mathrm{O}_{3}$ concentrations. As it can be seen, the plots consist of two superimposed semicircles with their centers lying below the real axis. An excellent agreement between the experimental and fitting data indicates that the equivalent circuit is reasonable. The relaxation process in the crystallite results in the high frequency arc, whereas the low frequency arc is related to the relaxation process in the crystal-glass interface. It can also be found that with the increase of $\mathrm{La}_{2} \mathrm{O}_{3}$ concentration, the portion of the crystallite impedance becomes smaller while that of the crystal-glass interface impedance increases. Especially, in the case of $1.0 \mathrm{~mol} \% \mathrm{La}_{2} \mathrm{O}_{3}$ addition, the crystallite semicircle is very small and the most contribution of the impedance is represented by the $R Q$ network responsible for the crystal-glass interface.

Impedance analysis reveals that for the $\mathrm{La}_{2} \mathrm{O}_{3}$-doped BST glassceramics the crystal-glass interface resistivity is higher than the corresponding crystallite resistivity depending on the temperature. These results can be described by an equivalent circuit that
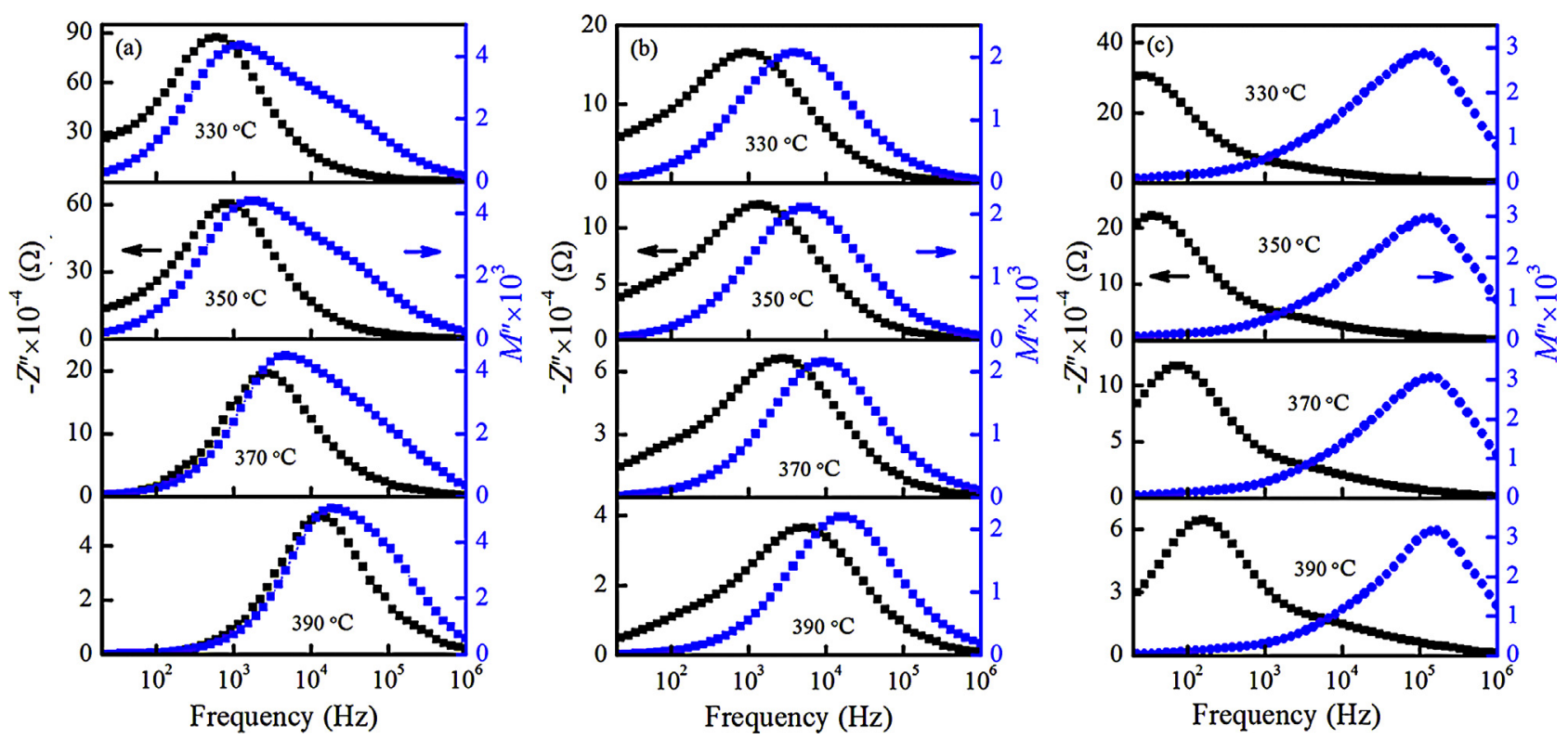

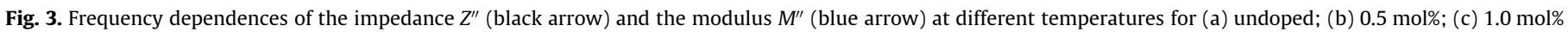
$\mathrm{La}_{2} \mathrm{O}_{3}$-doped BST glass-ceramics. (For interpretation of the references to colour in this figure legend, the reader is referred to the web version of this article.) 

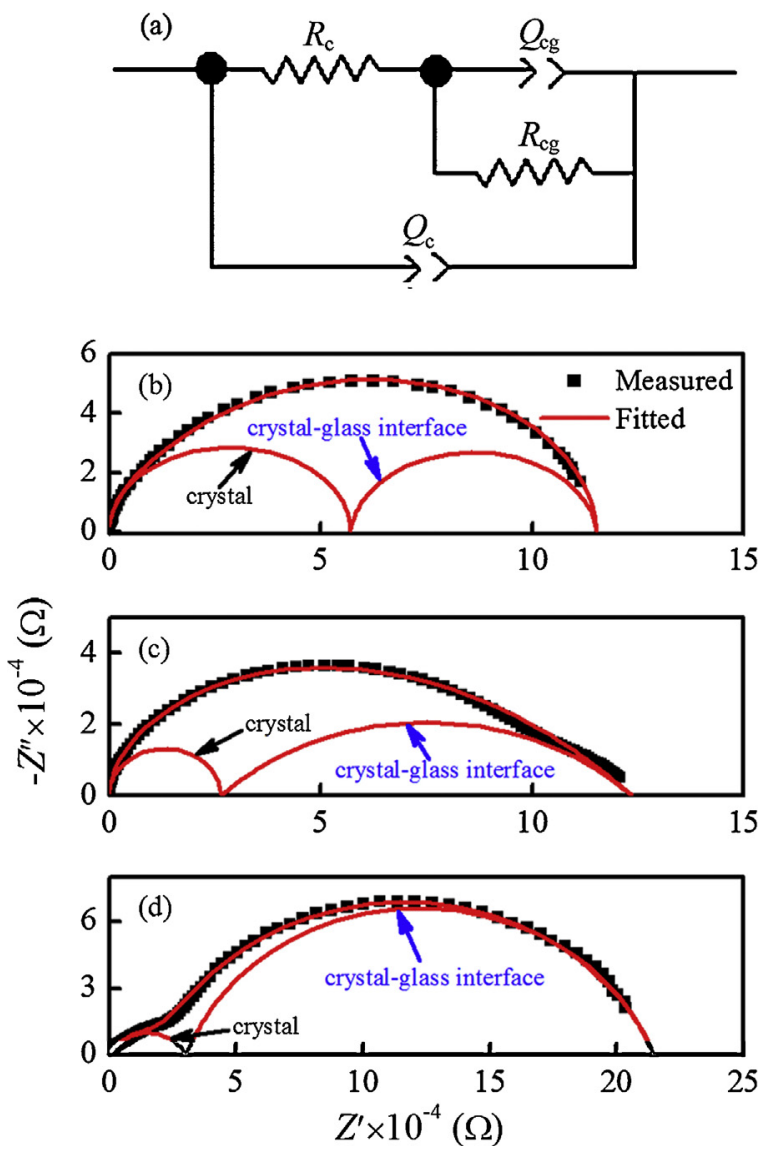

Fig. 4. (a) Equivalent circuit; complex impedance spectra of measured and fitted data for (b) undoped; (c) $0.5 \mathrm{~mol} \%$; (d) $1.0 \mathrm{~mol} \% \mathrm{La}_{2} \mathrm{O}_{3}$-doped samples at $390{ }^{\circ} \mathrm{C}$.

consists of a crystallite (c) branch and a crystal-glass interface (cg) branch shown in Fig. 4(a).

By fitting of the measured impedance data using the equivalent circuit shown in Fig. 4(a), the capacitance value can also be obtained from the following equation $[21,22]$ :

$C=\left(R^{n} Q\right)^{1 / n}$

where the parameter $n$ is the relaxation distribution parameter, $n=1$ for a pure capacitance, $n=0$ for a pure resistor and $n=0.5$ for a Warburg-type diffusion impedance.

The relaxation time of the crystallite $\left(\tau_{\mathrm{c}}\right)$ and the crystal-glass interface $\left(\tau_{\mathrm{cg}}\right)$ is defined as:

$\tau_{\mathrm{c}}=R_{\mathrm{c}} C_{\mathrm{c}}$

$\tau_{\mathrm{cg}}=R_{\mathrm{cg}} C_{\mathrm{cg}}$

The relaxation time was obtained from the nonlinear least squares fitting of the complex impedance data measured at various temperatures using Eqs. (5) and (6). The relaxation time of the crystallite and the crystal-glass interface obeys the Arrhenius relationship which is shown in Fig. 5:

$\tau=\tau_{0} \exp \left(-\frac{E}{k T}\right)$

where $\tau$ is the relaxation time, $\tau_{0}$ is the pre-exponential factor, $E$ is the activation energy, $k$ is the Boltzmann constant, and $T$ is the absolute temperature.

According to Eq. (7), the estimated activation energies of the crystallite and the crystal-glass interface for the samples with different $\mathrm{La}_{2} \mathrm{O}_{3}$ concentrations are listed in Table 1 . The activation
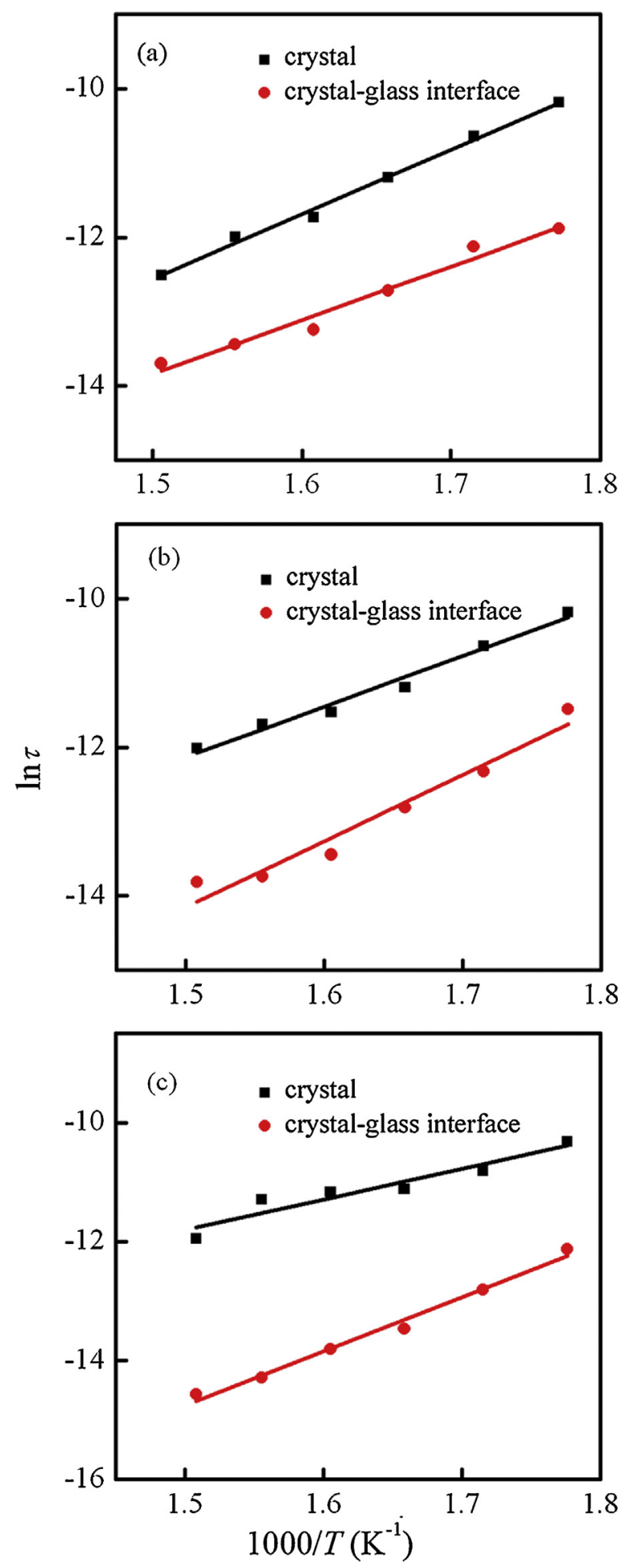

Fig. 5. Arrhenius plots of conductivity data for the BST glass-ceramics with different $\mathrm{La}_{2} \mathrm{O}_{3}$ concentrations: (a) undoped; (b) $0.5 \mathrm{~mol} \%$; (c) $1.0 \mathrm{~mol} \%$.

energy of the crystal-glass interface $\left(E_{\mathrm{cg}}\right)$ is between 0.65 and $0.79 \mathrm{eV}$, which is practically independent of $\mathrm{La}_{2} \mathrm{O}_{3}$ concentration. On the other hand, the activation energy of the crystallite $\left(E_{\mathrm{c}}\right)$ decreases from 0.63 to $0.44 \mathrm{eV}$ with the increase of $\mathrm{La}_{2} \mathrm{O}_{3}$ concentration, which indicates that the crystallite and the crystal-glass interface have different electrical transport characteristics [23].

The contribution of the crystal-glass interface resistance to the total resistance can be evaluated through blocking factor $\left(\alpha_{c g}\right)$ 


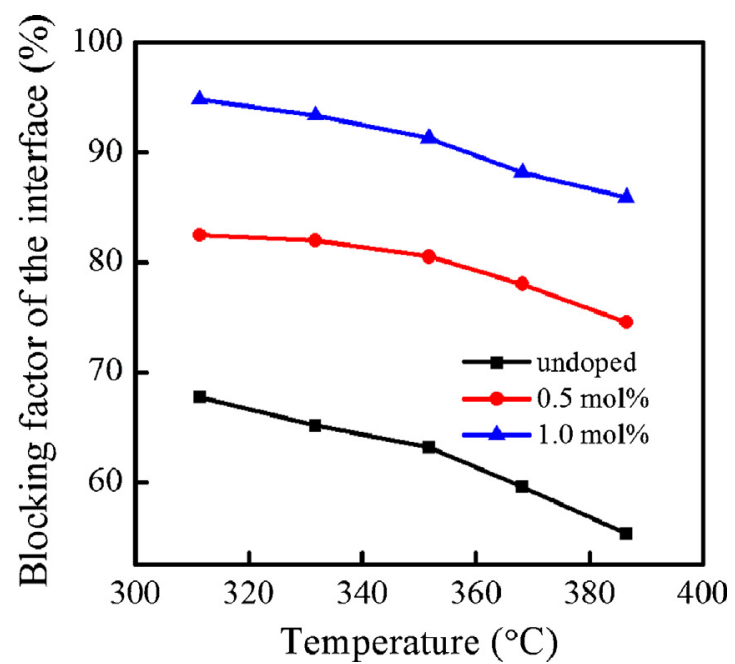

Fig. 6. Variation of the blocking factor with temperature for the BST glass-ceramics.

defined from the impedance spectroscopy parameters by [24]:

$\alpha_{\mathrm{cg}}=\frac{R_{\mathrm{cg}}}{R_{\mathrm{c}}+R_{\mathrm{cg}}}$

where $R_{\mathrm{c}}$ and $R_{\mathrm{cg}}$ are the crystallite and the crystal-glass interface resistances, respectively.

The blocking factor gives the fraction of electric carriers being blocked at the impermeable internal surfaces with respect to the total number of electric carriers in the samples. Fig. 6 shows the blocking factor as a function of temperature for the samples with 0 , 0.5 and $1.0 \mathrm{~mol} \% \mathrm{La}_{2} \mathrm{O}_{3}$ additions. It is shown that the blocking factor for the $1.0 \mathrm{~mol} \% \mathrm{La}_{2} \mathrm{O}_{3}$-doped sample is higher than that for the $0.5 \mathrm{~mol} \% \mathrm{La}_{2} \mathrm{O}_{3}$-doped sample over the studied temperature range.

Two basic models of the constriction zone model and the brick layer model have been proposed to describe the nature of the crystal-glass interface in the lanthanum-doped BST glass-ceramics and its influence on the blocking effect. As can be seen from Table 1 , in the undoped BST glass-ceramics the activation energy of the crystallite is close to that of the crystal-glass interface. These results are consistent with the constriction zone model [25], which demonstrated that the electrical contact of two phases is almost continuous or partially blocked by the interface. As the $\mathrm{La}_{2} \mathrm{O}_{3}$ concentration reaches $1.0 \mathrm{~mol} \%$, the activation energy of the crystal-glass interface becomes higher than that of the crystallite. This experimental finding is consistent with the brick layer model [26], which suggested that a continuous phase of high resistivity is present surrounding the crystallite. The obtained results demonstrate the validity of the brick layer approach to describe the blocking effect in the glass-ceramics.

The increase in the blocking effect of the crystal-glass interface with the increase of $\mathrm{La}_{2} \mathrm{O}_{3}$ concentration may be attributed to a combination of the mechanisms described below. Complex impedance spectroscopy suggests that there is a significant decrease in the crystallite activation energy associated with the

\section{Table 1}

Activation energy of the crystallite and the crystal-glass interface for the BST glassceramics with different $\mathrm{La}_{2} \mathrm{O}_{3}$ concentrations.

\begin{tabular}{lll}
\hline $\mathrm{La}_{2} \mathrm{O}_{3}$ concentration $(\mathrm{mol} \%)$ & $E_{\mathrm{c}}(\mathrm{eV})$ & $E_{\mathrm{cg}}(\mathrm{eV})$ \\
\hline 0 & 0.63 & 0.75 \\
0.5 & 0.58 & 0.65 \\
1.0 & 0.44 & 0.79
\end{tabular}

$\mathrm{La}_{2} \mathrm{O}_{3}$ concentration. The difference in the activation energy between the crystallite and the crystal-glass interface might indicate a reduction in ionic mobility in the crystal-glass interface. Such reduction may contribute to the increase of the blocking effect. On the other hand, the SEM analysis shows that the average crystallite size decreases as the $\mathrm{La}_{2} \mathrm{O}_{3}$ concentration increases. Since the crystal-glass interface is much more extensive for the glass-ceramics with small crystallite size than for those with large crystallite size, it can have significant impact on the electrical properties. This substantial increase in the crystal-glass interface area might create a zone of altered electrical properties which increases the blocking effect.

\section{Conclusions}

The microstructures and dielectric properties of the barium strontium titanate based glass-ceramics were investigated as a function of $\mathrm{La}_{2} \mathrm{O}_{3}$ concentration by XRD, SEM and impedance spectroscopy. It was demonstrated that $\mathrm{La}_{2} \mathrm{O}_{3}$ addition promotes the crystallization of the major crystalline phase, $(\mathrm{Ba}, \mathrm{Sr}) \mathrm{TiO}_{3}$, and decreases the average crystallite size. The characterization of the glass-ceramics by impedance spectroscopy through applying the equivalent circuit allows separating the individual contributions of the crystallite and the crystal-glass interface. The blocking effect of the crystal-glass interface on the ionic transport behavior was found in the $\mathrm{La}_{2} \mathrm{O}_{3}$ doped barium strontium titanate glass-ceramics. The decrease in the activation energy of the crystallite and the increase in the crystalglass interface area were believed to contribute to this blocking effect.

\section{Acknowledgements}

This work was supported by National Natural Science Foundation of China through NSFC-RFBR project (Grant No. 51111120091) and Russian Foundation for Basic Research (Grant No. 11-0291174-NSFC_a).

\section{References}

[1] Q. Tan, P. Irwin, Y. Cao, IEEJ Trans. FM 126 (2006) 1153-1159.

[2] M.J. Pan, C.A. Randall, IEEE Electr. Insul. Mag. 26 (2010) 44-50.

[3] A. Herczog, J. Am. Ceram. Soc. 47 (1964) 107-115.

[4] E.P. Gorzkowski, M.J. Pan, B. Bender, C.C.M. Wu, J. Electroceram. 18 (2007) 269276.

[5] Y. Zhang, J.J. Huang, T. Ma, X.R. Wang, C.S. Deng, X.M. Dai, J. Am. Ceram. Soc. 94 (2011) 1805-1810.

[6] A. Herczog, IEEE Trans. Parts Hybrids Packag. PHP-9 (1973) 247-256.

[7] P. Sooksaen, I.M. Reaney, D.C. Sinclair, J. Mater. Res. 20 (2005) 1316-1323.

[8] K. Kageyama, J. Takahashi, J. Am. Ceram. Soc. 87 (2004) 1602-1605.

[9] F.D. Morrison, D.C. Sinclair, A.R. West, J. Am. Ceram. Soc. 84 (2001) 474-476.

[10] F.D. Morrison, A.M. Coats, D.C. Sinclair, A.R. West,J. Electroceram. 6(2001)219-232.

[11] A.R. West, T.B. Adams, F.D. Morrison, D.C. Sinclair, J. Eur. Ceram. Soc. 24 (2004) 439-1448.

[12] Y. Zhang, T. Ma, X.R. Wang, Z.B. Yuan, Q. Zhang, J. Appl. Phys. 109 (2011) 084115.

[13] D. Kumar, C.R. Gautam, O. Parkash, Appl. Phys. Lett. 89 (2006) 112908.

[14] S. Guillemet-Fritsch, Z. Valdez-Nava, C. Tenailleau, T. Lebey, B. Durand, J.Y. ChaneChing, Adv. Mater. 20 (2008) 551-555.

[15] Z. Valdez-Nava, S. Guillemet-Fritsch, C. Tenailleau, T. Lebey, B. Durand, J.Y. ChaneChing, J. Electroceram. 22 (2009) 238-244.

[16] F.D. Morrison, D.C. Sinclair, A.R. West, J. Appl. Phys. 86 (1999) 6355-6366.

[17] A. Herczog, J. Am. Ceram. Soc. 67 (1984) 484-490.

[18] J.J. Huang, Y. Zhang, T. Ma, H.T. Li, L.W. Zhang, Appl. Phys. Lett. 96 (2010) 042902.

[19] R. Gerhardt, J. Phys. Chem. Solids 55 (1994) 1491-1506.

[20] K. Majhi, K.B.R. Varma, Int. J. Appl. Ceram. Technol. 7 (2010) E89-E97.

[21] X. Guo, J. Maier, J. Electrochem. Soc. 148 (2001) E121-E126.

[22] S.H. Yoon, C.A. Randall, K.H. Hur, J. Am. Ceram. Soc. 92 (2009) 1758-1765.

[23] Y.D. Xia, Z.G. Liu, Y. Wang, L. Shi, L. Chen, J. Yin, X.K. Meng, Appl. Phys. Lett. 91 (2007) 102904.

[24] C.R. Foschini, D.P.F. Souza, P.I. Paulin, J.A. Varela, J. Am. Ceram. Soc. 21 (2001) 1143-1150.

[25] J.E. Bauerle, J. Phys. Chem. Solids 30 (1969) 2657-2670.

[26] D.Y. Wang, A.S. Nowick, J. Solid State Chem. 35 (1980) 325-333. 